\title{
1 A healthy dietary pattern associates with a lower risk of a first clinical diagnosis of
}

2 central nervous system demyelination

3

4 Lucinda J Black ${ }^{1 *}$, Charlotte Rowley ${ }^{1}$, Jill Sherriff ${ }^{1}$, Gavin Pereira ${ }^{1}$, Anne-Louise

5 Ponsonby ${ }^{2,3}$, Ausimmune Investigator Group, Robyn M Lucas ${ }^{3,4}$

6

$7 \quad{ }^{1}$ School of Public Health, Curtin University, Perth, Australia

$8 \quad{ }^{2}$ Murdoch Children's Research Institute, University of Melbourne, Melbourne, Australia

$9{ }^{3}$ National Centre for Epidemiology and Population Health, Research School of Population

10 Health, The Australian National University, Canberra, Australia

$11{ }^{4}$ Centre for Ophthalmology and Visual Science, University of Western Australia, Perth,

12 Australia

$13 *$ Correspondence:

14 Lucinda Black

15 School of Public Health, Curtin University

16 Kent Street, Bentley, Western Australia 6102

17 Australia

18 Phone: 0892662523

19 lucinda.black@curtin.edu.au

20

21 Key Words: Multiple sclerosis, dietary patterns, Ausimmune Study, diet, nutrition, food 


\section{$1 \quad$ Abstract}

2 Background: The evidence associating diet and risk of MS is inconclusive.

3 Objective: We investigated associations between dietary patterns and risk of a first clinical

4 diagnosis of CNS demyelination (FCD), a common precursor to MS.

5 Methods: We used data from the 2003-2006 Ausimmune Study, a case-control study

6 examining environmental risk factors for FCD, with participants matched on age, sex and

7 study region. Using data from a food frequency questionnaire, dietary patterns were identified

8 using principal component analysis. Conditional logistic regression models $(n=698,252$

9 cases, 446 controls) were adjusted for history of infectious mononucleosis, serum 25-

10 hydroxyvitamin D concentrations, smoking, race, education, BMI and dietary misreporting.

11 Results: We identified two major dietary patterns - healthy (high in poultry, fish, eggs,

12 vegetables, legumes) and Western (high in meat, full fat dairy; low in wholegrains, nuts, fresh

13 fruit, low fat dairy), explaining $9.3 \%$ and $7.5 \%$ of variability in diet, respectively. A one-

14 standard deviation increase in the healthy pattern score was associated with a $25 \%$ reduced

15 risk of FCD (Adjusted Odds Ratio $0.75 ; 95 \%$ CI $0.60,0.94 ; P=0.011$ ). There was no

16 statistically significant association between the Western dietary pattern and risk of FCD.

17 Conclusion: Following healthy eating guidelines may be beneficial for those at high risk of

18 MS.

19

20

21

22 
24 There are a number of known environmental risk factors for MS, including low vitamin D

25 status and low sun exposure ${ }^{1}$, smoking ${ }^{2}$ and a history of infectious mononucleosis ${ }^{3}$.

26 Although diet may be a modifiable risk factor for MS, the current evidence focuses mainly on

27 single foods and nutrients, with inconclusive results ${ }^{4-7}$. Dietary pattern analysis has

28 advantages over the single food or single nutrient approach by capturing information about a

29 person's total diet, including the interactions that may occur between food components ${ }^{8}$. To

30 our knowledge, only two studies have investigated dietary patterns and risk of $\mathrm{MS}^{9,10}$, both of

31 which were case-control studies ( $\mathrm{n} \sim 70$ cases) of Iranian people with established MS. In these

32 studies, a Mediterranean diet was associated with reduced risk of $\mathrm{MS}^{9}$, as were traditional

33 Iranian, lacto-vegetarian and vegetarian dietary patterns ${ }^{10}$.

35 This study uses dietary intake data from the Ausimmune Study, a multicentre, incident case-

36 control study investigating the environmental risk factors for a first clinical diagnosis of CNS

37 demyelination (FCD) ${ }^{11}$. Associating dietary factors close to the time of FCD, rather than in

38 those with established MS, reduces the likelihood of reverse causation as participant

39 responses are less likely to be biased by disease-related changes in behaviour ${ }^{11}$. This is

40 important since dietary modification is common after a diagnosis of $\mathrm{MS}^{11,12}$. Previous

41 analysis of the Ausimmune Study showed a lower risk of FCD with higher intake of long-

42 chain omega-3 polyunsaturated fatty acids (PUFA) derived from fish ${ }^{4}$; we build on this work

43 by testing associations between dietary patterns and risk of FCD.

Methods

46

47 Design 
48 The 2003-2006 Ausimmune Study was a multicentre, case-control study conducted in four

49 regions of Australia: Brisbane city $\left(27^{\circ} \mathrm{S}\right)$, Newcastle region $\left(33^{\circ} \mathrm{S}\right)$, Geelong and the Western

50 districts of Victoria $\left(37^{\circ} \mathrm{S}\right)$, and the island of Tasmania $\left(43^{\circ} \mathrm{S}\right){ }^{11}$. Case participants $(n=282$,

$51 \quad 18-59$ years) were referred to the study as described previously, and the date of onset and

52 presenting symptoms suggestive of inflammatory CNS demyelination were confirmed by a

53 neurologist following a full history and neurological examination ${ }^{11}$. We used the date of the

54 MRI scan preceding diagnosis as the date of FCD, as these data were available for most

55 participants. The median (interquartile range (IQR)) time lag from the date of MRI scan by

56 the neurologist (the date of the diagnosis which brought the participants into the study) to the

57 study interview was 103 (153) days, with 116 case participants interviewed within 90 days of

58 MRI scan.

60 Case participants had had an incident FCD within the study period, including a classic first

61 demyelinating event (FDE; defined as a single, first, episode of clinical symptoms suggestive

62 of CNS demyelination; $n=216$ ), and primary progressive MS on neurological assessment on

63 study entry $(n=18)$. A further 48 participants were found to have a prior event highly

64 suggestive of CNS demyelination that had been unrecognised and not ascribed to

65 demyelination and thus unlikely to have triggered any behavioural changes. Control

66 participants $(n=558)$ were randomly selected from the general population to be matched on

67 age (within 2 years), sex and study region, via the Australian Electoral Roll (compulsory

68 registration for citizens $\geq 18$ years). Between one and four matched controls were matched to

69 each case, to maximize the study power, with more controls per case in regions with a lower

70 expected number of cases due to being either at higher latitude (and lower expected

71 incidence) or a smaller source population. However, these ratios were altered during the

72 course of the study for practical reasons: in 2006, all centres were recruiting two controls per 
case. Ethics approval was obtained from the nine Human Research Ethics Committees of the

74 participating institutions ${ }^{11}$. All participants gave written informed consent for the use of their 75 data.

77 The current study included participants who provided complete data on dietary intake and all covariates, and who were part of at least a matched control pair. Of the 840 participants (282 cases, 558 controls) in the Ausimmune Study, 791 participants (272 cases, 519 controls) provided dietary intake data; 743 participants (259 cases, 484 controls) of these provided data

81 for all covariates; and 698 participants ( 252 cases, 446 controls) of these were part of at least 82 a matched pair and thus formed the study cohort for this analysis.

Dietary assessment

The Cancer Council Victoria Dietary Questionnaire for Epidemiological Studies version 2 (DQESv2) was used to collect information on habitual dietary intakes in the 12 months prior to the study interview. The DQES is a self-administered, semi-quantitative, food frequency questionnaire (FFQ) designed for use in the ethnically-diverse adult Australian population, the

89 development of which has been outlined elsewhere ${ }^{13}$. The questionnaire has been validated relative to seven-day weighed food records in 63 women of child-bearing age, where it

91 performed as well as other validated FFQs: mean intakes from the weighted food record and 92 the DQES were within $\pm 20 \%$ for 21 of 27 nutrients ${ }^{14}$.

94 The frequencies of consumption of food items were recorded on a scale from 'never' to 'three or more times per day'. Portion size diagrams were used to determine respondents' average

96 portion size factor. Consumption of alcohol was recorded as the total number of glasses

97 usually drunk per day, and the maximum number of glasses drunk in any 24 hours. Intake of 
98101 food and beverage items was reported as grams per day, with nutrient intakes computed

99 primarily using composition data from the Australian NUTTAB 95 database $^{15}$.

100

101 Covariates

102 Participants completed a self-administered questionnaire, with variables categorised as

103 follows: race (Caucasian, other); history of infectious mononucleosis (yes, no, don't know);

104 highest level of education (year 10 or less, year 12 and Technical and Further Education,

105 university). Total number of years smoked was calculated minus any periods of abstinence.

106 Most participants (94\%) provided a blood sample: serum aliquots $(1 \mathrm{~mL})$ were stored at $-80^{\circ} \mathrm{C}$

107 and analysed for 25-hydroxyvitamin D (25(OH)D) concentrations using liquid

108 chromatography tandem mass spectrometry ${ }^{1}$. Since blood samples were taken at different

109 times of the year, serum $25(\mathrm{OH}) \mathrm{D}$ concentrations for case participants were deseasonalised

110 using the seasonal patterns of the control serum $25(\mathrm{OH}) \mathrm{D}$ concentrations ${ }^{1}$. The study nurse

111 measured height and weight, and body mass index (BMI) was calculated as weight in

112 kilograms divided by height in metres squared. Basal metabolic rate was calculated using the

113 equations developed by Harris and Benedict ${ }^{16}$ : males $\mathrm{h}=66.4730+13.7516 \mathrm{~W}+5.0033 \mathrm{~S}-$

114 6.7750A; females $\mathrm{h}=665.0955+9.5634 \mathrm{~W}+1.8496 \mathrm{~S}-4.6756 \mathrm{~A}\left(\right.$ where $\mathrm{h}=\mathrm{kcal}$ day $^{-1} ; \mathrm{W}=$ weight

115 in kilograms; $\mathrm{S}=$ stature in centimeters; $\mathrm{A}=$ =age in years). Under-reporters, plausible reporters

116 and over-reporters were classified using Goldberg cut-off points as follows ${ }^{17}$ : under-

117 reporters, below BMRx1.05; plausible reporters between BMRx1.05 and BMRx2.28; over-

118 reporters, above BMRx2.28. A three-category variable was created for dietary misreporting:

119 under-reporter, plausible reporter, and over-reporter.

120

121 Statistical analysis

122 
123 We categorised the 101 food and beverage items into 34 food groups (Table 1), based on

124 those used previously ${ }^{18}$. Each food group was energy-adjusted using the energy density

125 method ${ }^{19}$. The food group data for control participants only were entered into the PCA

126 procedure in Stata Statistical Software: Release $14^{20}$. The factor solution was limited to those

127 factors with an eigenvalue $>1.0$ and the number of factors to retain was based on the screeplot

128 and also on the interpretability of the obtained patterns ${ }^{21}$. The identified factors were

129 orthogonally rotated to improve their interpretability ${ }^{22}$. Food groups with a factor loading

$130 \geq 0.2$ were considered to contribute substantially to the pattern and were used to name each

131 pattern. Standardised factor scores were computed using the PCA procedure in Stata 14

132 software ${ }^{20}$, so that all participants were assigned a score for each dietary pattern, based on 133 their FFQ intakes.

135 Nutrient intakes derived from the FFQ were energy adjusted using the energy-density method

$136{ }^{19}$ and were described for the lowest and highest quintiles of each dietary pattern. Nutrient

137 densities with Normal distributions were reported as mean and standard deviation (SD), and

138 those with non-Normal distributions were reported as median and IQR. We compared nutrient

139 intakes between the five quintiles of each dietary pattern using one-way ANOVA for nutrients

140 with Normal distribution, and the Kruskal-Wallis test for nutrients with non-Normal

141 distribution.

142

143 Characteristics of cases and controls ( $n=698,252$ cases, 446 controls) were described as

144 frequency and percentage for categorical variables, mean and SD for continuous variables

145 with a Normal distribution, and median and IQR for continuous variables with a non-Normal

146 distribution. Characteristics of control participants who were included in the final model

147 ( $n=446)$ were compared with those who were excluded from the final model due to missing 
data or missing matched case participant $(n=112)$. Pearson's chi-square tests were used for

149 categorical variables, independent samples t-tests for continuous variables with Normal

150 distributions and Mann-Whitney U tests for continuous variables with non-Normal

151 distributions.

152

153 We used conditional logistic regression models (participants matched on age, sex and study 154 region) to estimate odds ratios (ORs), 95\% confidence intervals (95\% CI) and $p$ values for associations between dietary patterns and risk of FCD. Dietary pattern scores were analysed

156 both as continuous variables (where a one-unit increase was equivalent to a one-SD increase

157 in dietary pattern score) and as quintiles based on score thresholds for control participants.

159 Potential confounders were selected on the basis of: 1) being a known risk factor for MS

160 (history of infectious mononucleosis, serum 25-hydroxyvitamin D concentrations, total years

161 of smoking); 2) being a possible risk factor for MS and/or having a potential influence on

162 dietary patterns (race, BMI and education); and 3) accounting for the well-documented under-

163 reporting of energy intake by self-reported dietary methods (dietary misreporting) ${ }^{23}$. The

164 impact of the dietary patterns on each other was investigated by including all dietary patterns

165 simultaneously in the final models ${ }^{8}$. Model $1(n=698)$ was unadjusted; model $2(n=698)$ was

166 adjusted for history of infectious mononucleosis, serum 25-hydroxyvitamin D concentration,

167 total years of smoking, race, education and dietary misreporting; model 3 ( $n=698)$ was

168 additionally adjusted for all dietary patterns; model 4 was additionally adjusted for BMI

$169(n=698)$. We tested for an interaction between the dietary pattern score and BMI using an

170 interaction term in the models. To test whether any associations differed by sex, we ran

171 models in males and females separately and examined differences in the effect estimates. 
173 We conducted the following sensitivity analyses: a) excluding participants with implausible

174 energy intakes $(<3,000 \text { or }>20,000 \mathrm{~kJ} / \text { day; } n=4 \text { cases, } 9 \text { controls })^{22}(n=677,247$ cases, 430

175 controls); b) including only case participants who completed the study interview within 90

176 days from the date of MRI scan ( $n=321,116$ cases, 205 controls); and c) including only case

177 participants with a classic FDE ( $n=528,193$ cases, 335 controls). Data were analysed using

178 Stata 14 software ${ }^{20}$.

179

$180 \quad$ Results

181 Participant characteristics

182 Table 2 shows the characteristics of case and control participants. Most participants (95\%)

183 were Caucasian. Case participants were more likely than controls to have a history of

184 infectious mononucleosis, lower serum 25(OH)D concentrations, and to have completed

185 education beyond year 10. There was no difference between the control participants who were

186 included in the final model $(n=446)$ and those who were excluded from the final model

187 ( $n=112)$ with respect to the following characteristics: history of infectious mononucleosis

188 ( $\mathrm{p}=0.76)$, serum 25-hydroxyvitamin D concentration $(\mathrm{p}=0.11)$, total years of smoking

$189(p=0.97)$, race $(p=0.17)$, age $(p=0.59)$, education $(p=0.17)$, and BMI $(p=0.49)$. Compared with

190 those excluded from the final model, control participants included in the final model were

191 more likely to be male $(\mathrm{p}=0.015)$ and to be from Brisbane or Tasmania $(\mathrm{p}<0.001)$.

192

193 Dietary patterns

194 PCA identified two major dietary patterns, explaining $9.3 \%$ and $7.5 \%$ of variability in diet

195 (Table 3). The first (healthy) pattern was characterised by a higher intake of poultry, grilled

196 and tinned fish, eggs, yellow and red vegetables, cruciferous vegetables, leafy green

197 vegetables, other vegetables and legumes. The second (Western) pattern was characterised by 
198 a higher intake of red meat, processed meat and full fat dairy, and was low in wholegrains,

199 nuts, fresh fruit and low fat dairy.

200

201 Compared with those in the lowest quintile of the healthy pattern, participants in the highest

202 quintile had: lower intakes of total energy; lower energy-adjusted intakes of total fat, saturated

203 fat and monounsaturated fat; and higher energy-adjusted intakes of long-chain omega-3

204 PUFA, protein, dietary fibre, and various vitamins and minerals (Table 4). Compared with

205 those in the lowest quintile of the Western pattern, participants in the highest quintile had:

206 higher intakes of total energy; higher energy-adjusted intakes of total fat, saturated fat and

207 monounsaturated fat; and lower energy-adjusted intakes of PUFA, long-chain omega-3

208 PUFA, carbohydrate, dietary fibre, and various vitamins and minerals.

209

210 Dietary patterns and risk of FCD

211 In the unadjusted model (Model 1), a one-SD increase in the healthy pattern score was

212 associated with a 17\% (Adjusted Odds Ratio (AOR) 0.83 ; 95\% CI 0.69, 0.99) reduced risk of

213 FCD (Table 5). A one-SD increase in the healthy pattern score was associated with a 24\%

214 (AOR 0.76; 95\% CI 0.62, 0.94) reduced risk of FCD when adjusted for potential confounders

215 (Model 2), and a 25\% (AOR 0.75; 95\% CI 0.60, 0.94) reduced risk of FCD when further

216 adjusted for the Western dietary pattern (Model 3) and BMI (Model 4). Compared with the

217 lowest quintile of the healthy dietary pattern score, the risk of FCD was $47 \%$ (AOR $0.53 ; 95 \%$

218 CI $0.29,0.96$ ) lower in the fourth quintile and 55\% (AOR $0.45 ; 95 \%$ CI $0.24,0.83$ ) lower in

219 the highest quintile in the fully adjusted model (Model 4). There was no statistically

220 significant interaction between the healthy dietary pattern score and BMI in the model using

221 the dietary pattern score as a continuous variable $(\mathrm{p}=0.09)$ and as quintiles. We found no

222 evidence of a statistically significant association between a Western dietary pattern and risk of 
223 FCD, nor was there a statistically significant interaction between the Western dietary pattern

224 score and BMI in the model using the dietary pattern score as a continuous variable $(\mathrm{p}=0.11)$

225 and as quintiles.

226

227 Similar findings were observed in the sensitivity analyses of those with plausible energy

228 intakes (Table 6a) and those who completed the study interview within 90 days from the date

229 of MRI scan (Table 6b). In the classic FDE group, the findings were similar but with wider

230 confidence intervals (Table 6c).

231

232 When stratified by sex, a one-SD increase in the healthy pattern score was associated with a

$23328 \%$ reduced risk of FCD in women in the fully adjusted model (AOR $0.72 ; 95 \%$ CI 0.56 ,

$2340.93 ; P=0.011 ; n=189$ cases, 339 controls). There was an 9\% reduced risk of FCD in men but

235 this association was statistically non-significant (AOR $0.91 ; 95 \%$ CI $0.43,1.93 ; P=0.808$;

236 ( $n=63$ cases, 107 controls). Supplementary Figure 1 shows histograms of the healthy dietary

237 pattern score for cases and controls, stratified by sex. There was no statistically significant

238 association between a Western dietary pattern and risk of FCD in models stratified by sex

239 (women: AOR 0.93; 95\% CI 0.75, 1.16; $P=0.512$; men: AOR 1.19; 95\% CI 0.73, 1.94;

$240 \quad P=0.495)$.

242 Discussion

243 Our results suggest a protective effect of a healthy dietary pattern (high in poultry, fish, eggs,

244 vegetables and legumes) on risk of FCD. The association was independent of history of

245 infectious mononucleosis, serum 25-hydroxyvitamin D concentration, total years of smoking,

246 race, education, BMI, dietary misreporting and Western dietary pattern score. The association

247 was stronger in women than in men; however, the large overlap in the interval estimates 
suggests that the lack of statistical association for men was possibly due to the lower sample

249 size for men due to the female case excess. We did not observe any statistically significant associations between a Western dietary pattern and risk of FCD. The two major dietary patterns we identified were similar to the 'healthy' and 'Western' patterns identified in other studies of adults, as reviewed previously ${ }^{24}$. Although the small amount of total variability in diet explained by the dietary patterns is a limitation, this is similar to other studies of dietary patterns derived by PCA $^{25,26}$.

Our findings are similar to the study by Sedaghat and colleagues ${ }^{9}$ which showed that, in a hospital-based case-control study of people with MS in Iran ( $n=70$ cases, 142 controls), a high quality Mediterranean diet was associated with reduced risk of MS. In that study, the Mediterranean diet (high in vegetables, legumes, fruits, nuts, fish and a high ratio of unsaturated to saturated fatty acids; and low in dairy, meat and meat products and refined grains) was assessed using a modified version of the 9-Unit dietary score ${ }^{24}$. Our results support these findings since a healthy dietary pattern - high in vegetables, legumes and fish is similar to a Mediterranean diet.

265 Jahromi and colleagues ${ }^{10}$ used factor analysis to identify dietary patterns in a case-control 266 study of women with relapsing/remitting MS ( $n=77$ cases, 75 controls). Three dietary patterns 267 were inversely associated with risk of MS: 1) traditional (high in low-fat dairy products, red meat, vegetable oil, onion, wholegrain, soy, refined grains, organ meats, coffee and legumes); 2) lacto-vegetarian (high in nuts, fruits, French fries, coffee, sweets and desserts, vegetables and high-fat dairy products); and 3) vegetarian (high in green leafy vegetables, hydrogenated

271 fats, tomato, yellow vegetables, fruit juices, onion and other vegetables). A Western dietary 272 pattern (high in animal fats, potato, meat products, sugars and hydrogenated fats, and low in 
wholegrains) was positively associated with risk of MS. A limitation of the study was that case participants had been diagnosed with the disease up to three years previously and some changes in dietary habits occurred in a number of case participants after the onset of the 276 disease.

A major strength of the Ausimmune Study was its incident case-control design, where collection of dietary data was soon after the FCD, rather than in people with established MS. Most of the limited dietary research in relation to MS has been conducted in individuals who have established MS. The proportion of people making dietary changes after a diagnosis of MS ranges from $17 \%{ }^{27}$ to $42 \%{ }^{12}$, making reverse causation (i.e. that the diagnosis has led to behaviour changes in dietary intake) an important consideration. By recruiting participants with FCD, rather than MS, the possibility of reverse causation is reduced, since the participants did not have a medical diagnosis of MS and minimal time had passed since they were initially assessed by a medical specialist. However, there is some evidence to suggest the existence of a multiple sclerosis prodrome, with degenerative processes and symptoms, including fatigue and depression, possibly starting years prior to clinical manifestation of demyelination ${ }^{28-30}$. Prodromal symptoms, such as fatigue and depression, may lead to differences in eating prior to a FCD; therefore, we cannot rule out the possibility of reverse causation.

293 A further limitation of our study is the widely acknowledged under-reporting of energy intake

294 from self-reported dietary assessment methods ${ }^{23}$. It is well-known that energy under-

295 reporting of foods is selective, with unhealthy and snack foods more likely to be forgotten 296 during dietary reporting ${ }^{31,32}$. Although this may potentially bias the analysis of dietary 297 patterns, it is likely that recall error in our study was similar for case and control participants. 
298 Similarly, although portion size photos in self-administered FFQs have limited value for

299 ranking individuals correctly according to their actual portion sizes ${ }^{33}$, recall error was likely

300 to be similar for case and control participants.

301

302 Other limitations of our study include potential residual confounding and lack of

303 generalisability. We cannot rule out residual confounding, whereby those following a healthy

304 dietary pattern have other unmeasured lifestyle characteristics that reduce the risk of FCD.

305 However, with the exception of smoking, most lifestyle characteristics - including BMI,

306 alcohol intake and physical activity - were not associated with risk of FCD in previous

307 analysis of the Ausimmune Study ${ }^{34}$. Lastly, these results may not be generalisable to other

308 populations - the dietary patterns were derived specifically from this group of participants

309 who were living in Australia and were predominantly Caucasian; the diets of people of other

310 races and those living in other countries are likely to be different from the diets followed by

311 our participants.

312

313 In summary, our results suggest that following a healthy diet characterised by poultry, fish,

314 eggs, vegetables and legumes may lower the risk of FCD. Such a diet is in line with

315 recommendations for the general population, including the Australian Dietary Guidelines ${ }^{35}$.

316 In the absence of convincing evidence to the contrary, healthy eating guidelines designed for

317 the general population are currently the best available dietary recommendations for people at

318 high risk of MS. Given that less than $4 \%$ of the Australian population follow the Australian

319 Dietary Guidelines ${ }^{35}$, improved nutrition education for people at high risk of MS onset may

320 be beneficial in helping them follow a healthy diet, and may subsequently reduce their risk of

321 FCD, or of MS. 


\section{Acknowledgements}

324 We thank the participants of the Ausimmune Study.

326 We would like to acknowledge and thank the physicians who notified case participants to the 327 Ausimmune Study:

328 Jeffrey Blackie FRACP, Richard Bourke FRACGP, John Cameron MD, Ross Carne MD, Ben 329 Clark FRANZCO, Steven Collins MD, Diana Conrad FRANZCO, Michael Coroneos 330 FRACS, Nicholas Downie FRANZCO, David Floate FRACP, Peter Gates FRACP, Kerryn 331 Green FRACP, Erwin Groeneveld FRANZCO, John Harrison FRANZCO, Michael Haybittel 332 FRANZCO, Robert Henderson FRACP, John Henshaw MMed, James Hurley MD, Dean 333 Jones FRACP, Michael Katekar MBBS, Anthony Kemp FRACP, Mark King FRACP, George 334 Kiroff FRACS, Brett Knight FRACP, Thomas Kraemer FRACP, Cecile Lander FRACP, 335 Jeannette Lechner-Scott FRACP, Andre Loiselle FRACP, Paul McCartney FRANZCO, 336 Pamela McCombe PhD, Mark McGree FRANZCO, David McKnight FRANZCO, Daniel 337 McLaughlin PhD, Satish Nagarajah MBBS, Rob Nightingale FRACP, ,Terence O’Brien MD, 338 John O'Sullivan MD, Gregory Outteridge FRANZCO, Anthony Pane FRANZCO, Mark 339 Parsons FRACP, Melinda Pascoe FRACP, David Prentice PhD, Richard Ralph FRACGP, 340 Stephen Read FRACP, John Richmond FRACP, Ian Routley FRANZCO, Timothy Ruddle 341 FRANZCO, Noel Saines FRACP, Stan Siejka MBBS (dec), Christopher Staples FRACP, 342 Paul Talman FRACP, Don Todman FRACP, Nitin Verma FRANZCO, Brendan Vote

343 FRANZCO, Michael Waldie FRANZCO, Michael Weetch FRACP, Rodney Westmore 344 FRANZCO, Andrew Wong FRACP;

346 the local research officers: 
347 Susan Agland BN, Barbara Alexander BN, Marcia Davis MD, Zoe Dunlop BN, Rosalie Scott

348 BN, Marie Steele RN, Catherine Turner MPH\&TM, Brenda Wood RN;

349

350 and the Ausimmune Study project officers during the course of the study:

351 Jane Gresham MA(Int Law), Camilla Jozwick BSc(Hons), Helen Rodgers RN.

352

353 The Ausimmune Investigator Group includes the following investigators:

354 Dr Caron Chapman, Barwon Health, Geelong, Victoria, Australia

355 Prof Alan Coulthard, Royal Brisbane and Women's Hospital and the University of

356 Queensland, Brisbane, Queensland, Australia

357 Prof Keith Dear, School of Public Health, University of Adelaide, South Australia, Australia

358 Prof Terry Dwyer, Murdoch Childrens Research Institute, University of Melbourne,

359 Melbourne, Victoria, Australia

360 Prof Trevor Kilpatrick, Centre for Neuroscience, University of Melbourne, Melbourne,

$361 \quad$ Australia

362 Prof Robyn Lucas, National Centre for Epidemiology and Population Health, The Australian

363 National University, Canberra, Australian Capital Territory, Australia

364 Prof Tony McMichael (dec), National Centre for Epidemiology and Population Health, The

365 Australian National University, Canberra, Australian Capital Territory, Australia

366 Prof Michael P Pender, Royal Brisbane and Women's Hospital and the University of

367 Queensland, Brisbane, Queensland, Australia

368 Prof Anne-Louise Ponsonby, Murdoch Childrens Research Institute, University of

369 Melbourne, Melbourne, Victoria, Australia

370 Prof Bruce Taylor, Menzies Research Institute Tasmania, University of Tasmania, Hobart,

371 Tasmania, Australia 
372 A/Prof Patricia Valery, Menzies School of Health Research, Brisbane, Queensland,

373 Australia

374 A/Prof Ingrid van der Mei, Menzies Research Institute Tasmania, University of Tasmania,

375 Hobart, Tasmania, Australia

376 Dr David Williams, Hunter Health, Newcastle, New South Wales, Australia

377

378 Conflict of interest: There are no conflicts of interest.

379

380 Funding: Funding for the Ausimmune Study was provided by the National Multiple Sclerosis

381 Society of the United States of America, the National Health and Medical Research Council

382 of Australia and Multiple Sclerosis Research Australia. LJB is supported by a Multiple

383 Sclerosis Western Australia Postdoctoral Fellowship. RML and ALP are supported by a

384 National Health and Medical Research Council of Australia Senior Research Fellowship.

385 Funding bodies had no role in the design or conduct of the study; collection, management,

386 analysis or intepretation of data; or preparation, review or approval of the manuscript.

387

388 Author contributions: The Ausimmune Investigator Group, LJB and JS designed the study;

389 CR and LJB analysed the data; CR and LJB wrote the manuscript; GP provided statistical

390 support; JS, GP, ALP and RML provided critical revision of the manuscript for important

391 intellectual content. All authors have approved the manuscript and it has not been published

392 elsewhere. 
394 1. Lucas RM, Ponsonby AL, Dear K, et al. Sun exposure and vitamin D are independent

2. O'Gorman C, Broadley SA. Smoking and multiple sclerosis: evidence for latitudinal and temporal variation. Journal of neurology. 2014;261(9):1677-1683.

3. Levin LI, Munger KL, Rubertone MV, et al. Temporal relationship between elevation of epstein-barr virus antibody titers and initial onset of neurological symptoms in multiple sclerosis. Jama. 2005;293(20):2496-2500.

4. Hoare S, Lithander F, van der Mei I, Ponsonby AL, Lucas R. Higher intake of omega3 polyunsaturated fatty acids is associated with a decreased risk of a first clinical diagnosis of central nervous system demyelination: Results from the Ausimmune Study. Multiple sclerosis (Houndmills, Basingstoke, England). 2016;22(7):884-892.

5. Farez MF, Fiol MP, Gaitan MI, Quintana FJ, Correale J. Sodium intake is associated with increased disease activity in multiple sclerosis. Journal of neurology, neurosurgery, and psychiatry. 2015;86(1):26-31.

6. Baarnhielm M, Olsson T, Alfredsson L. Fatty fish intake is associated with decreased occurrence of multiple sclerosis. Multiple sclerosis (Houndmills, Basingstoke, England). 2014;20(6):726-732.

7. Carlson NG, Rose JW. Antioxidants in multiple sclerosis: do they have a role in therapy? CNS Drugs. 2006;20(6):433-441.

8. McNaughton SA. Dietary patterns and diet quality: approaches to assessing complex exposures in nutrition. Australasian Epidemiologist. 2010;17.1:35-37.

9. Sedaghat F, Jessri M, Behrooz M, Mirghotbi M, Rashidkhani B. Mediterranean diet adherence and risk of multiple sclerosis: a case-control study. Asia Pacific journal of clinical nutrition. 2016;25(2):377-384.

10. Jahromi SR, Toghae M, Jahromi MJ, Aloosh M. Dietary pattern and risk of multiple sclerosis. Iranian journal of neurology. 2012;11(2):47-53.

11. Lucas R, Ponsonby AL, McMichael A, et al. Observational analytic studies in multiple sclerosis: controlling bias through study design and conduct. The Australian Multicentre Study of Environment and Immune Function. Multiple sclerosis (Houndmills, Basingstoke, England). 2007;13(7):827-839.

12. Riemann-Lorenz K, Eilers M, von Geldern G, Schulz KH, Kopke S, Heesen C. Dietary Interventions in Multiple Sclerosis: Development and Pilot-Testing of an Evidence Based Patient Education Program. PloS one. 2016;11(10):e0165246.

13. Ireland P, Jolley D, Giles G, et al. Development of the Melbourne FFQ: a food frequency questionnaire for use in an Australian prospective study involving an ethnically diverse cohort. Asia Pacific journal of clinical nutrition. 1994;3(1):19-31.

14. Hodge A, Patterson AJ, Brown WJ, Ireland P, Giles G. The Anti Cancer Council of Victoria FFQ: relative validity of nutrient intakes compared with weighed food records in young to middle-aged women in a study of iron supplementation. Australian and New Zealand journal of public health. 2000;24(6):576-583.

15. Lewis J, Milligan G, Hunt A. NUTTAB 95 Nutrient Data Table for Use in Australia. Canberra1995.

16. Harris J, Benedict F. A biometric study of basal metabolism in man. Wasthington D.C.: Carnegie Institute of Washington; 1919.

17. Goldberg GR, Black AE, Jebb SA, et al. Critical evaluation of energy intake data using fundamental principles of energy physiology: derivation of cut-off limits to identify under-reporting. European Journal of Clinical Nutrition. 1991;45:569-581. 
18. Ambrosini GL, O'Sullivan TA, de Klerk NH, Mori TA, Beilin LJ, Oddy WH. Relative validity of adolescent dietary patterns: a comparison of a FFQ and $3 \mathrm{~d}$ food record. $\mathrm{Br}$ J Nutr. 2011;105(4):625-633. doi: 610.1017/S0007114510004137.

19. Willett WC, Howe GR, Kushi LH. Adjustment for total energy intake in epidemiologic studies. Am J Clin Nutr. 1997;65(4 Suppl):1220S-1228S; discussion 1229S-1231S.

20. StataCorp CS, TX: StataCorp LP. Stata Statistical Software: Release 14. College Station, TX2015.

21. Fransen HP, May AM, Stricker MD, et al. A posteriori dietary patterns: how many patterns to retain? J Nutr. 2014;144(8):1274-1282. doi: 1210.3945/jn.1113.188680. Epub 182014 May 188628.

22. Ambrosini GL, Fritschi L, de Klerk NH, Mackerras D, Leavy J. Dietary patterns identified using factor analysis and prostate cancer risk: a case control study in Western Australia. Ann Epidemiol. 2008;18(5):364-370.

23. Black AE, Prentice AM, Goldberg GR, et al. Measurements of total energy expenditure provide insights into the validity of dietary measurements of energy intake. Journal of the American Dietetic Association. 1993;93:572-579.

24. Newby PK, Tucker KL. Empirically derived eating patterns using factor or cluster analysis: a review. Nutr Rev. 2004;62(5):177-203.

25. Thorpe MG, Milte CM, Crawford D, McNaughton SA. A comparison of the dietary patterns derived by principal component analysis and cluster analysis in older Australians. Int J Behav Nutr Phys Act. 2016;13:30.

26. Schrijvers JK, McNaughton SA, Beck KL, Kruger R. Exploring the Dietary Patterns of Young New Zealand Women and Associations with BMI and Body Fat. Nutrients. 2016;8(pii):E450.

27. Brenton JN, Goldman MD. A study of dietary modification: Perceptions and attitudes of patients with multiple sclerosis. Multiple sclerosis and related disorders. 2016;8:54-57.

28. Berger JR, Pocoski J, Preblick R, Boklage S. Fatigue heralding multiple sclerosis. Multiple sclerosis (Houndmills, Basingstoke, England). 2013;19(11):1526-1532.

29. Byatt N, Rothschild AJ, Riskind P, Ionete C, Hunt AT. Relationships between multiple sclerosis and depression. The Journal of neuropsychiatry and clinical neurosciences. 2011;23(2):198-200.

30. Wijnands JMA, Kingwell E, Zhu F, et al. Health-care use before a first demyelinating event suggestive of a multiple sclerosis prodrome: a matched cohort study. The Lancet Neurology. 2017;16(6):445-451.

31. Funtikova AN, Gomez SF, Fito M, Elosua R, Benitez-Arciniega AA, Schroder H. Effect of energy under-reporting on secular trends of dietary patterns in a mediterranean population. PloS one. 2015;10(5):e0127647.

32. Heitmann BL, Lissner L. Dietary underreporting by obese individuals--is it specific or non-specific? BMJ (Clinical research ed). 1995;311(7011):986-989.

33. Haraldsdottir J, Tjonneland A, Overvad K. Validity of individual portion size estimates in a food frequency questionnaire. International journal of epidemiology. 1994;23(4):786-796.

34. Ponsonby AL, Lucas RM, Dear K, et al. The physical anthropometry, lifestyle habits and blood pressure of people presenting with a first clinical demyelinating event compared to controls: the Ausimmune study. Multiple sclerosis (Houndmills, Basingstoke, England). 2013;19(13):1717-1725.

35. National Health and Medical Research Council. Australian Dietary Guidelines. Canberra2013. 
491 
Table 1: Categorisation of 101 foods into 34 food groups

\begin{tabular}{|c|c|c|}
\hline & Food group & Foods \\
\hline 1 & Red meat & Beef, veal, lamb, pork \\
\hline 2 & Processed meat & Bacon, ham, salami, sausage \\
\hline 3 & Poultry & Chicken \\
\hline 4 & Take away & Meat pie, pizza, hamburger \\
\hline 5 & Grilled/tinned fish & Grilled fish, tinned fish \\
\hline 6 & Fried fish & Fried fish \\
\hline 7 & Eggs & Eggs \\
\hline 8 & Wholegrains & Rye bread, multigrain bread, wholegrain bread, high fibre bread, All-bran, bran flakes, Weetbix, porridge, muesli \\
\hline 9 & Refined grains & Crackers, pasta, rice, cornflakes, white bread \\
\hline 10 & Yellow and red vegetables & Pepper, carrot, pumpkin, tomato \\
\hline 11 & Cruciferous vegetable & Cabbage, cauliflower, broccoli \\
\hline 12 & Leafy green vegetables & Lettuce, spinach \\
\hline 13 & Potato & Potato \\
\hline 14 & Fried potato & Chips \\
\hline 15 & Other vegetables & Cucumber, celery, beetroot, onion, garlic, mushroom, zucchini, sprouts \\
\hline 16 & Legumes & Peas, green beans, baked beans, other beans, tofu \\
\hline 17 & Nuts & Nuts \\
\hline 18 & Fresh fruit & Orange, apple, pear, banana, melon, pineapple, strawberry, apricot, peach, avocado, mango \\
\hline 19 & Tinned fruit & Tinned fruit \\
\hline 20 & Juice & Fruit juice \\
\hline 21 & Low fat dairy & Reduced fat milk, skim milk, soya milk, low fat cheese, ricotta cheese \\
\hline 22 & Full fat dairy & Full fat milk, cream cheese, soft cheese, firm cheese, hard cheese, yoghurt \\
\hline 23 & Sweetened dairy & Flavoured milk, ice cream \\
\hline 24 & Sauces & Tomato sauce \\
\hline 25 & Crisps & Crisps \\
\hline
\end{tabular}


26 Confectionary

27 Cakes biscuits \& sweet pastries

28 Added sugar

29 Saturated spreads

30 Unsaturated spreads

31 Other spreads

32 Wine

33 Spirits

34 Beer
Chocolate

Sweet biscuits, cakes

Jam, sugar

Butter, margarine, margarine blends

Polyunsaturated margarine, monounsaturated margarine

Peanut butter, vegemite

Red wine, white wine, fortified wine

Spirits

Low strength beer, full strength beer 
Table 2. Characteristics of participants $(n=698 ; 252$ cases, 226 controls $)$ included in the current study

\begin{tabular}{|c|c|c|}
\hline & Case & Control \\
\hline \multicolumn{3}{|l|}{ Sex, $\%(n)^{\mathrm{a}}$} \\
\hline Male & $25.0(63)$ & $24.0(107)$ \\
\hline Female & $75.0(189)$ & $76.0(339)$ \\
\hline Age, year, mean $(\mathrm{SD})^{\mathrm{a}}$ & $38.7(9.7)$ & $40.0(9.6)$ \\
\hline \multicolumn{3}{|l|}{ Study region, $\%(n)^{\mathrm{a}}$} \\
\hline Brisbane $\left(27^{\circ} \mathrm{S}\right)$ & $34.1(86)$ & $37.4(167)$ \\
\hline Newcastle $\left(33^{\circ} \mathrm{S}\right)$ & $12.3(31)$ & $14.4(64)$ \\
\hline Geelong $\left(37^{\circ} \mathrm{S}\right)$ & $23.8(60)$ & $24.7(110)$ \\
\hline Tasmania $\left(43^{\circ} \mathrm{S}\right)$ & $29.8(75)$ & $23.5(105)$ \\
\hline \multicolumn{3}{|l|}{ Race, $\%(n)$} \\
\hline Caucasian & $96.4(243)$ & $94.0(419)$ \\
\hline Other & $3.6(9)$ & $6.0(27)$ \\
\hline \multicolumn{3}{|l|}{ History of infectious mononucleosis, \% $(n)$} \\
\hline No & $65.1(164)$ & $79.2(353)$ \\
\hline Yes & $27.8(70)$ & $16.1(72)$ \\
\hline Don't know & $7.1(18)$ & $4.7(21)$ \\
\hline $\begin{array}{l}\text { Serum } 25(\mathrm{OH}) \mathrm{D} \text { concentrations, mean } \\
(\mathrm{SD})\end{array}$ & $76.8(29.7)$ & $81.8(30.7)$ \\
\hline Total years of smoking, median (IQR) & $5.4(18.7)$ & $2.0(15.0)$ \\
\hline \multicolumn{3}{|l|}{ Education, \% $(n)$} \\
\hline Year 10 or less & $24.6(62)$ & $33.2(148)$ \\
\hline Year 12 and TAFE & $49.6(125)$ & $41.7(186)$ \\
\hline University & $25.8(65)$ & $25.1(112)$ \\
\hline Body mass index, median (IQR) & $25.9(7.6)$ & $25.5(7.4)$ \\
\hline \multicolumn{3}{|l|}{ Dietary misreporting, $\%(n)$} \\
\hline Under-reporter & $42.5(107)$ & $40.4(180)$ \\
\hline Plausible reporter & $55.6(140)$ & $57.2(255)$ \\
\hline Over-reporter & $2.0(5)$ & $2.5(11)$ \\
\hline
\end{tabular}

${ }^{\text {a }}$ Case and control participants were matched on sex, age (within two years) and study region FCD, first clinical diagnosis of central nervous system demyelination; SD, standard deviation; IQR, interquartile range; $25(\mathrm{OH}) \mathrm{D}, 25$-hydroxyvitamin D; TAFE, Technical And Further Education 
Table 3. Factor loadings of the food groups in the two major dietary patterns identified with principal component analysis

\begin{tabular}{|c|c|c|}
\hline Food group & Healthy & Western \\
\hline Red meat & 0.14 & $0.30^{\mathrm{a}}$ \\
\hline Processed meat & 0.12 & $0.34^{\mathrm{a}}$ \\
\hline Poultry & $0.21^{\mathrm{a}}$ & 0.18 \\
\hline Take away & -0.03 & 0.19 \\
\hline Grilled/tinned fish & $0.30^{\mathrm{a}}$ & -0.03 \\
\hline Fried fish & 0.05 & 0.16 \\
\hline Eggs & $0.35^{\mathrm{a}}$ & 0.12 \\
\hline Wholegrains & -0.01 & $-0.42^{\mathrm{a}}$ \\
\hline Refined grains & -0.11 & 0.12 \\
\hline Yellow and red vegetables & $0.23^{\mathrm{a}}$ & -0.08 \\
\hline Cruciferous vegetable & $0.25^{\mathrm{a}}$ & 0.07 \\
\hline Leafy green vegetables & $0.40^{\mathrm{a}}$ & 0.01 \\
\hline Potato & -0.12 & 0.04 \\
\hline Fried potato & -0.11 & 0.18 \\
\hline Other vegetables & $0.43^{\mathrm{a}}$ & -0.04 \\
\hline Legumes & $0.20^{\mathrm{a}}$ & -0.01 \\
\hline Nuts & 0.13 & $-0.26^{\mathrm{a}}$ \\
\hline Fresh fruit & 0.17 & $-0.29^{\mathrm{a}}$ \\
\hline Canned fruit & -0.02 & -0.10 \\
\hline Juice & -0.12 & -0.14 \\
\hline Low fat dairy & 0.01 & $-0.40^{\mathrm{a}}$ \\
\hline Full fat dairy & -0.05 & $0.23^{\mathrm{a}}$ \\
\hline Sweetened dairy & -0.02 & 0.10 \\
\hline Sauces & -0.12 & 0.02 \\
\hline Crisps & -0.18 & 0.04 \\
\hline Confectionary & 0.01 & 0.10 \\
\hline Cakes biscuits \& sweet pastries & -0.13 & 0.01 \\
\hline Added sugar & -0.07 & 0.07 \\
\hline Saturated spreads & -0.12 & 0.002 \\
\hline Unsaturated spreads & -0.04 & -0.04 \\
\hline Other spreads & -0.09 & -0.002 \\
\hline Wine & 0.06 & -0.15 \\
\hline Spirits & -0.002 & 0.05 \\
\hline Beer & -0.09 & 0.04 \\
\hline Variance explained (\%) & 9.3 & 7.5 \\
\hline
\end{tabular}

${ }^{\mathrm{a}}$ Food groups with a factor loading $\geq 0.2$ (higher intake) were considered characteristic of the dietary pattern 
Table 4. Nutrient intakes (as energy density) for the lowest and highest quintiles of the two dietary pattern scores

\begin{tabular}{|c|c|c|c|c|c|c|}
\hline & \multicolumn{3}{|c|}{ Healthy pattern } & \multicolumn{3}{|c|}{ Western pattern } \\
\hline & Lowest quintile & Highest quintile & $P$ & Lowest quintile & Highest quintile & $P$ \\
\hline Total energy intake $(\mathrm{kJ})^{\mathrm{a}}$ & $8938.8(5701.2)$ & $5492.7(2202.8)$ & $<0.001$ & $6211.9(2818.1)$ & $8644.7(5150.8)$ & $<0.001$ \\
\hline Total fat density $(\mathrm{g} / \mathrm{MJ} / \mathrm{d})^{\mathrm{b}}$ & $41.7(6.0)$ & $37.6(7.0)$ & $<0.001$ & $34.4(6.5)$ & $44.4(4.5)$ & $<0.001$ \\
\hline Saturated fat density $(\mathrm{g} / \mathrm{MJ} / \mathrm{d})^{\mathrm{b}}$ & $18.5(3.7)$ & $14.3(3.8)$ & $<0.001$ & $12.5(3.0)$ & $19.8(3.0)$ & $<0.001$ \\
\hline Monounsaturated fat density $(\mathrm{g} / \mathrm{MJ} / \mathrm{d})^{\mathrm{b}}$ & $14.3(2.3)$ & $13.8(3.0)$ & 0.028 & $12.3(2.8)$ & $15.7(1.9)$ & $<0.001$ \\
\hline Polyunsaturated fat density $(\mathrm{g} / \mathrm{MJ} / \mathrm{d})^{\mathrm{a}}$ & $5.2(2.5)$ & $5.3(2.6)$ & 0.313 & $5.8(3.7)$ & $4.9(1.6)$ & 0.013 \\
\hline Long-chain omega 3 fatty acid density $(\mathrm{mg} / \mathrm{MJ} / \mathrm{d})^{\mathrm{a}}$ & $84.9(109.4)$ & $296.7(300.8)$ & $<0.001$ & $221(247.9)$ & $120.1(147.1)$ & $<0.001$ \\
\hline Protein density $(\mathrm{g} / \mathrm{MJ} / \mathrm{d})^{\mathrm{b}}$ & $41.6(6.1)$ & $53.0(8.8)$ & $<0.001$ & $47.6(7.4)$ & $48.1(8.8)$ & 0.585 \\
\hline Carbohydrate density $(\mathrm{g} / \mathrm{MJ} / \mathrm{d})^{\mathrm{b}}$ & $102.1(16.0)$ & $102.0(15.9)$ & 0.538 & $113.6(18.5)$ & $91.9(14.8)$ & $<0.001$ \\
\hline Dietary fibre density $(\mathrm{g} / \mathrm{MJ} / \mathrm{d})^{\mathrm{b}}$ & $8.8(2.3)$ & $14.4(3.8)$ & $<0.001$ & $14.6(3.4)$ & $8.4(2.2)$ & $<0.001$ \\
\hline Calcium density $(\mathrm{mg} / \mathrm{MJ} / \mathrm{d})^{\mathrm{b}}$ & $456.2(145.4)$ & $566.5(183.3)$ & $<0.001$ & $627.2(195.0)$ & $430.5(138.4)$ & $<0.001$ \\
\hline Magnesium density $(\mathrm{mg} / \mathrm{MJ} / \mathrm{d})^{\mathrm{b}}$ & $131.8(20.1)$ & $184.5(31.5)$ & $<0.001$ & $192.5(26.0)$ & $127.3(17.0)$ & $<0.001$ \\
\hline Zinc density $(\mathrm{mg} / \mathrm{MJ} / \mathrm{d})^{\mathrm{b}}$ & $5.3(1.0)$ & $6.8(1.3)$ & $<0.001$ & $6.1(1.0)$ & $6.3(1.4)$ & 0.368 \\
\hline Iron density $(\mathrm{mg} / \mathrm{MJ} / \mathrm{d})^{\mathrm{a}}$ & $5.6(1.5)$ & $7.4(2.0)$ & $<0.001$ & $7.3(2.1)$ & $5.8(1.5)$ & $<0.001$ \\
\hline Beta-carotene density $(\mathrm{mcg} / \mathrm{MJ} / \mathrm{d})^{\mathrm{a}}$ & $934.0(783.3)$ & $2139.8(947.6)$ & $<0.001$ & $1785.7(1037.6)$ & $1132.1(1033.7)$ & $<0.001$ \\
\hline Thiamin density $(\mathrm{mg} / \mathrm{MJ} / \mathrm{d})^{\mathrm{b}}$ & $0.76(0.24)$ & $0.83(0.21)$ & 0.026 & $0.9(0.2)$ & $0.7(0.2)$ & $<0.001$ \\
\hline Riboflavin density $(\mathrm{mg} / \mathrm{MJ} / \mathrm{d})^{\mathrm{b}}$ & $1.2(0.3)$ & $1.4(0.3)$ & $<0.001$ & $1.5(0.4)$ & $1.1(0.3)$ & $<0.001$ \\
\hline Niacin equivalents density $(\mathrm{mg} / \mathrm{MJ} / \mathrm{d})^{\mathrm{b}}$ & $18.1(2.8)$ & $22.6(3.3)$ & $<0.001$ & $21.0(3.2)$ & $20.0(3.4)$ & 0.115 \\
\hline Folate density $(\mathrm{mcg} / \mathrm{MJ} / \mathrm{d})^{\mathrm{b}}$ & $124.4(30.8)$ & $179.0(42.0)$ & $<0.001$ & $179.9(39.7)$ & $122.4(28.6)$ & $<0.001$ \\
\hline Vitamin $\mathrm{C}$ density $(\mathrm{mg} / \mathrm{MJ} / \mathrm{d})^{\mathrm{a}}$ & $45.4(33.8)$ & $83.0(41.2)$ & $<0.001$ & $80.4(53.2)$ & $48.2(31.5)$ & $<0.001$ \\
\hline Vitamin E density $(\mathrm{mg} / \mathrm{MJ} / \mathrm{d})^{\mathrm{b}}$ & $3.0(0.6)$ & $4.0(1.3)$ & $<0.001$ & $4.0(1.2)$ & $2.9(0.6)$ & $<0.001$ \\
\hline
\end{tabular}

${ }^{\mathrm{a}}$ Median (interquartile range), $P$-values derived from Kruskal-Wallis test; ${ }^{\mathrm{b}}$ Mean (standard deviation), $P$-values derived from one-way Anova 
Table 5. Associations between dietary patterns (healthy and Western) and risk of FCD in participants of the Ausimmune Study

\begin{tabular}{|c|c|c|c|c|c|c|c|c|}
\hline & \multicolumn{2}{|c|}{ Model 1: unadjusted } & \multicolumn{2}{|c|}{ Model $2^{\mathrm{a}}$ : partially adjusted } & \multicolumn{2}{|c|}{ Model $3^{b}$ : partially adjusted } & \multicolumn{2}{|c|}{ Model $4^{c}$ : fully adjusted } \\
\hline & OR $(95 \% \mathrm{CI})$ & $\boldsymbol{P}$ & AOR (95\% CI) & $\boldsymbol{P}$ & $\operatorname{AOR}(95 \% \mathrm{CI})$ & $\boldsymbol{P}$ & $\operatorname{AOR}(95 \% \mathrm{CI})$ & $P$ \\
\hline$n$ (cases, controls) & $698(252,446)$ & & $698(252,446)$ & & $698(252,446)$ & & $698(252,446)$ & \\
\hline Healthy (per SD) & $0.83(0.69,0.99)$ & 0.042 & $0.76(0.62,0.94)$ & 0.013 & $0.75(0.60,0.94)$ & 0.011 & $0.75(0.60,0.94)$ & 0.011 \\
\hline Quintile 1 & Reference & & Reference & & Reference & & Reference & \\
\hline Quintile 2 & $0.80(0.49,1.31)$ & 0.377 & $0.77(0.46,1.31)$ & 0.342 & $0.75(0.44,1.29)$ & 0.300 & $0.75(0.44,1.29)$ & 0.300 \\
\hline Quintile 3 & $0.91(0.56,1.49)$ & 0.714 & $0.75(0.44,1.27)$ & 0.282 & $0.72(0.42,1.23)$ & 0.226 & $0.72(0.42,1.23)$ & 0.226 \\
\hline Quintile 4 & $0.66(0.40,1.11)$ & 0.199 & $0.56(0.31,0.99)$ & 0.046 & $0.53(0.29,0.96)$ & 0.035 & $0.53(0.29,0.96)$ & 0.035 \\
\hline Quintile 5 & $0.59(0.35,1.01)$ & 0.056 & $0.48(0.26,0.86)$ & 0.014 & $0.45(0.24,0.83)$ & 0.011 & $0.45(0.24,0.83)$ & 0.011 \\
\hline$P($ trend $)$ & & 0.047 & & 0.009 & & 0.007 & & 0.007 \\
\hline Western (per SD) & $0.97(0.82,1.14)$ & 0.676 & $1.00(0.84,1.20)$ & 0.971 & $0.94(0.77,1.13)$ & 0.504 & $0.94(0.77,1.13)$ & 0.506 \\
\hline Quintile 1 & Reference & & Reference & & Reference & & Reference & \\
\hline Quintile 2 & $0.99(0.61,1.60)$ & 0.962 & $1.06(0.64,1.76)$ & 0.830 & $0.91(0.54,1.55)$ & 0.738 & $0.91(0.54,1.55)$ & 0.738 \\
\hline Quintile 3 & $0.97(0.60,1.57)$ & 0.907 & $1.03(0.62,1.70)$ & 0.918 & $0.88(0.52,1.48)$ & 0.621 & $0.88(0.52,1.48)$ & 0.621 \\
\hline Quintile 4 & $0.67(0.39,1.14)$ & 0.137 & $0.75(0.42,1.32)$ & 0.317 & $0.65(0.36,1.17)$ & 0.146 & $0.65(0.36,1.17)$ & 0.147 \\
\hline Quintile 5 & $0.91(0.55,1.50)$ & 0.701 & $0.99(0.57,1.72)$ & 0.966 & $0.80(0.44,1.44)$ & 0.451 & $0.80(0.44,1.44)$ & 0.451 \\
\hline$P($ trend $)$ & & 0.324 & & 0.601 & & 0.247 & & 0.248 \\
\hline
\end{tabular}

${ }^{a}$ Adjusted for history of infectious mononucleosis, serum 25-hydroxyvitamin D concentrations, total years of smoking, race, education and dietary misreporting; ${ }^{\mathrm{b}}$ As previous and additionally adjusted for the alternate dietary pattern (both patterns included in the model); ${ }^{\mathrm{c}}$ As previous and additionally adjusted for body mass index

FCD, first clinical diagnosis of central nervous system demyelination 
Table 6. Associations between dietary patterns (healthy and Western) and (a) risk of FCD excluding participants with implausible energy intakes $(<3,000$ or $>20,000 \mathrm{~kJ} / \mathrm{day})$, (b) risk of FCD in case participants who completed the study interview within 90 days from the date of MRI scan, and (c) risk of FDE

\begin{tabular}{|c|c|c|c|c|c|c|c|c|}
\hline & \multicolumn{2}{|c|}{ Model 1: unadjusted } & \multicolumn{2}{|c|}{ Model $2^{\mathrm{a}}$ : partially adjusted } & \multicolumn{2}{|c|}{ Model $3^{\mathrm{b}}$ : partially adjusted } & \multicolumn{2}{|c|}{ Model $4^{c}$ : fully adjusted } \\
\hline & OR (95\% CI) & $\boldsymbol{P}$ & AOR (95\% CI) & $\boldsymbol{P}$ & $\operatorname{AOR}(95 \% \mathrm{CI})$ & $\boldsymbol{P}$ & AOR (95\% CI) & $\boldsymbol{P}$ \\
\hline \multicolumn{9}{|c|}{ a) risk of FCD excluding participants with implausible energy intakes } \\
\hline$n$ (cases, controls) & $677(247,430)$ & & $677(247,430)$ & & $677(247,430)$ & & $677(247,430)$ & \\
\hline Healthy (per SD) & $0.86(0.71,1.04)$ & 0.127 & $0.78(0.62,0.98)$ & 0.030 & $0.76(0.60,0.96)$ & 0.024 & $0.76(0.60,0.97)$ & 0.025 \\
\hline Western (per SD) & $0.96(0.81,1.13)$ & 0.598 & $1.00(0.84,1.20)$ & 0.965 & $0.93(0.77,1.13)$ & 0.489 & $0.93(0.77,1.13)$ & 0.475 \\
\hline \multicolumn{9}{|c|}{ b) risk of FCD in case participants who completed the study interview within 90 days from the date of MRI scan } \\
\hline$n$ (cases, controls) & $321(116,205)$ & & $321(116,205)$ & & $321(116,205)$ & & $321(116,205)$ & \\
\hline Healthy (per SD) & $0.78(0.59,1.04)$ & 0.106 & $0.67(0.46,0.96)$ & 0.029 & $0.65(0.44,0.95)$ & 0.027 & $0.62(0.42,0.91)$ & 0.015 \\
\hline Western (per SD) & $0.97(0.76,1.25)$ & 0.552 & $1.00(0.75,1.32)$ & 0.972 & $0.91(0.67,1.23)$ & 0.545 & $0.88(0.65,1.17)$ & 0.372 \\
\hline \multicolumn{9}{|l|}{ c) risk of FDE } \\
\hline$n$ (cases, controls) & $528(193,335)$ & & $528(193,335)$ & & $528(193,335)$ & & $528(193,335)$ & \\
\hline Healthy (per SD) & $0.83(0.67,1.02)$ & 0.082 & $0.81(0.63,1.04)$ & 0.099 & $0.78(0.60,1.02)$ & 0.071 & $0.79(0.61,1.03)$ & 0.085 \\
\hline Western (per SD) & $0.96(0.80,1.15)$ & 0.670 & $0.96(0.78,1.18)$ & 0.675 & $0.90(0.72,1.13)$ & 0.363 & $0.90(0.72,1.12)$ & 0.336 \\
\hline
\end{tabular}

${ }^{a}$ Adjusted for history of infectious mononucleosis, serum 25-hydroxyvitamin D concentrations, total years of smoking, race, education and dietary misreporting; ${ }^{\mathrm{b}}$ As previous and additionally adjusted for the alternate dietary pattern (both patterns included in the model); ${ }^{\mathrm{c}}$ As previous and additionally adjusted for body mass index

FCD, first clinical diagnosis of central nervous system demyelination; FDE, incident classic first demyelinating event 


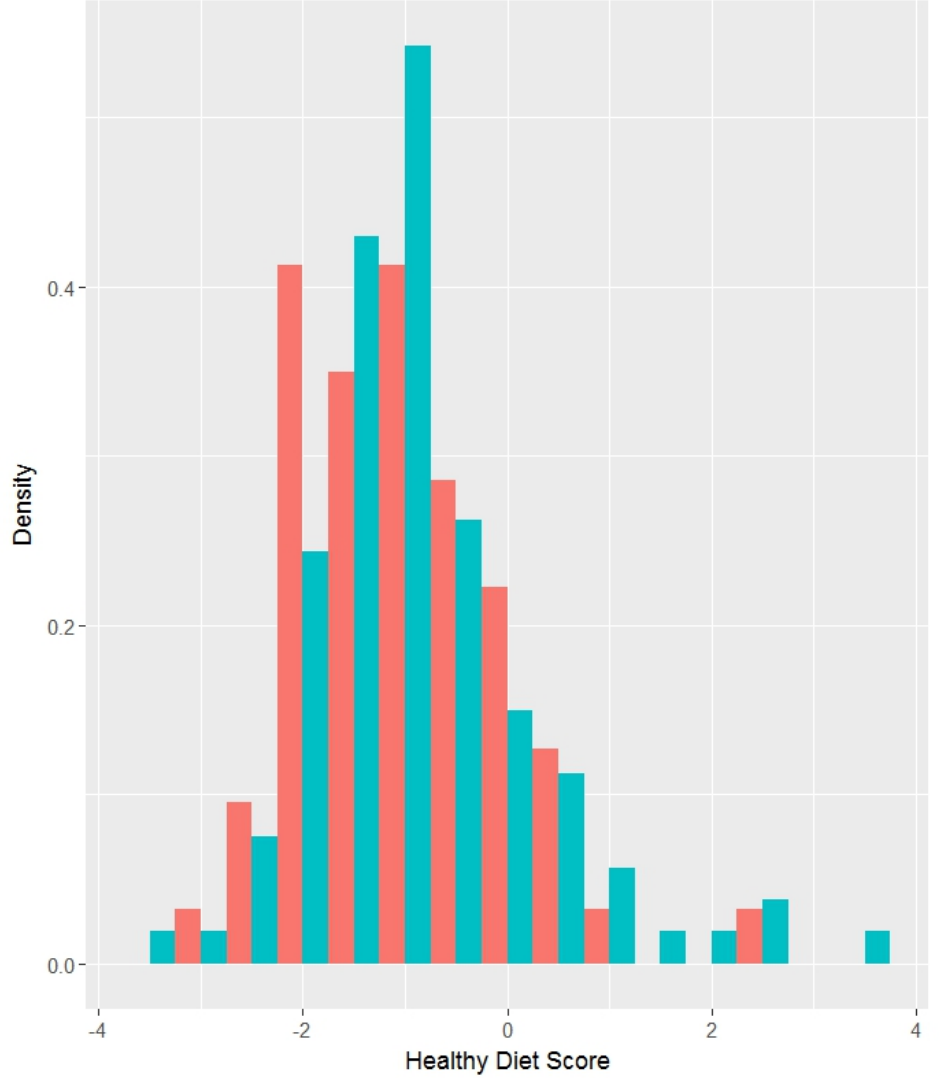

a)

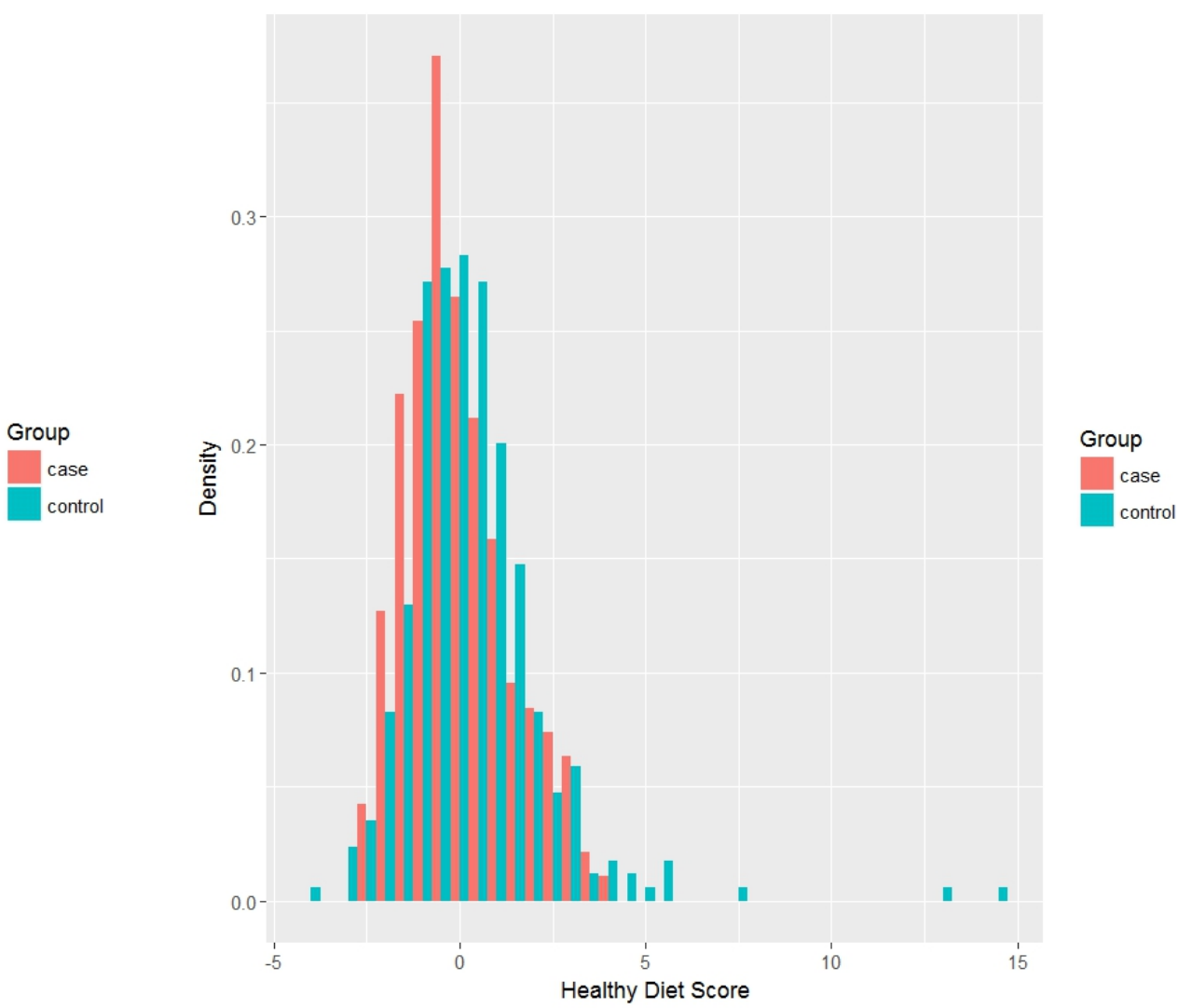

b)

Supplementary Figure 1. Histograms of the healthy dietary pattern score for case and control participants of the Ausimmune Study for a) men ( $n=63$ cases, 107 controls) and b) women ( $n=189$ cases, 339 controls) 